\title{
CUSTOMER RELATIONSHIP MANAGEMENT (CRM) UNTUK PRODUK APLIKASI HOTELMU BERBASIS WEBSITE
}

\author{
Nur Alamsyah', Ahmad Saripudin ${ }^{2}$ \\ Fakultas Ilmu Komputer Universitas Nasional PASIM \\ Jalan Dakota No 8a. Kota Bandung Jawa Barat 40175 Telepon (022) 6072803 \\ nuralamsyah.bdg@gmail.com, ahmadsyarifudin798@gmail.com
}

\begin{abstract}
Abstrak
Penelitian ini bertujuan untuk membangun Sistem Informasi Customer Relationship Management untuk Produk Hotelmu yang dapat memudahkan dalam mengelola data pelanggan, data proposal, data kontrak dan data faktur. Dan Sistem Informasi Customer Relationship Management ini juga diharapkan dapat memudahkan pelanggan aplikasi hotelmu untuk menyampaikan keluhan, saran dan kritiknya. Sistem informasi ini akan dirancang dan dibangun dengan model proses Prototype dan metode pengembangan object oriented. Adapun cara menggambarkan hasil analisis dengan pendekatan Object Oriented ini penyusun menggunakan Unified Modeling Language (UML), antara lain Use Case Diagram, Activity Diagram, Sequence Diagram, dan Class Diagram. Kemudian akan dibangun dengan bahasa pemrograman CodeIgniter dan basis data MySQL. Sistem Informasi Customer Relationship Management (CRM), diharapkan dapat memudahkan dalam mengontrol semua klien Hotelmu dengan efektif dan efisien. Sehingga proses rekapitulasi data klien, pembuatan proposal, kontrak, dan faktur menggunakan aplikasi khusus, dan data-data tersimpan dalam database dengan aman dan dapat dicari kapan saja dengan efisien.
\end{abstract}

Kata Kunci : CRM, Hotelmu, Object Oriented, Prototype

\begin{abstract}
This research aims to build information systems Customer Relationship Management for the Hotelmu Products in managing customers data, proposals data, contracts data and invoicing data. Information systems and Customer Relationship Management are also expected to facilitate the Hotelmu customers' application to convey complaints, suggestions and criticism. This information system will be designed and built with the Prototype process models and methods of object oriented development. To describe the results of analysis by Object Oriented approach to these compilers uses Unified Modeling Language (UML), among others, Use Case diagrams, Activity diagrams, Sequence Diagrams, and Class diagrams. Then it will be built with CodeIgniter programming language and MYSQL as database. Information system Customer Relationship Management (CRM), is expected to ease the controlling all Hotelmu clients effectively and efficiently. So the recapitulation process of client data, making proposals, contracts, and invoices use a special application, and the data stored in the database safely and it can be searched at any time by efficiently.
\end{abstract}

Keywords : CRM, Hotelmu, Object Oriented, Prototype 
JURNAL NUANSA INFORMATIKA

Volume 14 Nomor 1, Januari 2020

\section{PENDAHULUAN}

Sistem Informasi merupakan salah satu hal terpenting dalam suatu perusahaan ataupun organisasi. Dengan adanya sistem informasi, maka perusahaan atau organisasi dapat menjamin kualitas informasi yang disajikan dan dapat mengambil keputusan berdasarkan informasi tersebut dengan efisien. Seiring perkembangan teknologi, maka kebutuhan akan informasi yang cepat, tepat dan akurat sangat diperlukan. Oleh karena itu, keberadaan sistem informasi sudah menjadi kebutuhan mutlak bagi semua perusahaan dalam menjalankan proses bisnisnya.

Hotelmu merupakan aplikasi hotel yang dibuat untuk hotel-hotel bintang dua kebawah. Sudah banyak pelanggan yang menggunakan jasa Hotelmu. Namun, proses bisnis Hotelmu tidak terkontrol dengan baik. Pencatatan data-data pelanggan masih manual dalam Microsoft Excel. Bahkan, sering terjadi miskomunikasi antara Tim Marketing, Admin, dan Manager. Karena sering terjadi miskomunikasi antar-departemen, terkadang kontrak dan faktur tidak dikirim. Padahal klien sudah deal dengan tim Marketing dan sudah menggunakan sistem Hotelmu.

Berdasarkan latar belakang masalah yang telah diuraikan diatas, dapat diidentifikasikan masalah-masalah seperti berikut :

1. Bagaimana membangun Sistem Informasi CRM yang dapat mempermudah dalam mengontrol pelanggan Hotelmu, mengelola data proposal, mengelola data kontrak, dan mengelola data faktur.

2. Bagaimana membangun Sistem Informasi CRM yang dapat mempermudah pelanggan dalam menyampaikan keluhan, saran dan kritiknya.

\section{METODE PENELITIAN}

\subsection{Metode pengumpulan data}

p-ISSN : 1858-3911, e-ISSN : 2614-5405

https://journal.uniku.ac.id/index.php/ilkom

Adapun metode pengumpulan data yang digunakan penyusun adalah sebagai berikut :

1. Observasi

Observasi lapangan dengan melakukan pengamatan langsung terhadap sistem yang sedang berjalan sesuai dengan alur data dan prosedur di lingkungan $\mathrm{CV}$. Kawatama Sinergi.

2. Wawancara

Mencari data melalui wawancara langsung dengan orang-orang yang terlibat langsung di lingkungan Obje penelitian.

3. Studi Pustaka

Dengan mengumpulkan data dan informasi mengenai prosedur sistem yang berjalan, analisis perancangan sistem berorientasi objek dan bahasa pemograman yang dapat dijadikan acuan pembahasan dalam masalah ini.

\subsection{Model proses}

Model proses yang digunakan dalam pengembangan sistem ini akan menggunakan proses Prototyping. Prototyping adalah pendekatan pengembangan perangkat lunak dimana pelanggan mendefinisikan serangkaian target umum untuk proyek tetapi tidak mengidentifikasi spesifikasi kebutuhan yang rinci (Pressman, 2010: 43). Pengembang mungkin tidak yakin akan keefektifan algoritma, struktur yang harus diambil oleh komunikasi manusia-mesin, atau apa yang diinginkan oleh pelanggan dalam proses karena pelanggan sendiri masih memiliki penggambaran yang kabur secara rinci-nya. Di bawah ini adalah ilustrasi pendekatan prototyping :

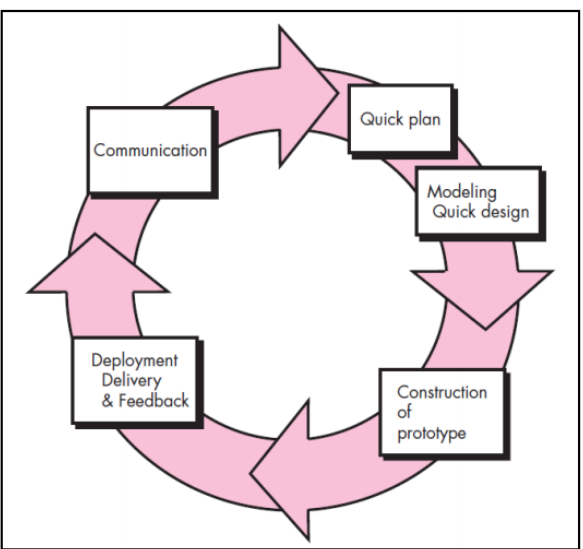

Gambar 2.1 Paradigma Prototyping (Pressman) 
JURNAL NUANSA INFORMATIKA

Volume 14 Nomor 1, Januari 2020

Berdasarkan ilustrasi diatas, tahapan-tahapan prototyping dimulai dengan :

1) Komunikasi antara tim pengembang software dengan para pelanggan. Dimana pelanggan menetapkan tujuan umum untuk program tersebut.

2) Perencanaan cepat. Tim pengembang software akan melakukan pertemuan dengan para stakeholder untuk mendefinisikan sasaran keseluruhan untuk software yang akan dikembangkan, mengidentifikasi spesifikasi kebutuhan yang diketahui saat ini.

3) Kemudian, perencanaan cepat dan pemodelan desain cepat dilakukan.

4) Pembangunan prototipe. Suatu rancangan cepat berupa rancangan antarmuka pengguna/format tampilan. Rancangan cepat akan memulai konstruksi pembuatan prototipe yang akan diserahkan kepada para stakeholder dan dievaluasi. Kemudian dilakukan umpan balik untuk memperhalus dan memenuhi spesifikasi kebutuhan para stakeholder.

Ini dilakukan secara iterasi, prosesnya berulang hingga prototipe akhirnya dapat dirilis sebagai program / sistem yang stabil. Dengan menggunakan pendekatan ini, pengembang dapat mengambil keputusan cepat tentang kebutuhan pelanggan yang seharusnya.

\subsection{Metode pengembangan sistem}

Model pengembangan sistem yang digunakan dalam penelitian ini adalah dengan melakukan pendekatan Object Oriented. Adapun cara menggambarkan hasil analisis dengan pendekatan Object Oriented ini penyusun menggunakan unified modeling language (UML), antara lain Use Case Diagram, Activity Diagram, Sequence Diagram, dan Class Diagram.

\section{HASIL DAN PEMBAHASAN}

\subsection{Perancangan Aplikasi}

\subsubsection{Use Case Diagram}

Use Case Diagram merupakan pemodelan untuk menggambarkan kelakuan (behavior) sistem yang akan dibuat. Use Case Diagram mendeskripsikan sebuah interaksi antara satu atau lebih aktor dengan sistem yang akan dibuat.
p-ISSN : 1858-3911, e-ISSN : 2614-5405

https://journal.uniku.ac.id/index.php/ilkom

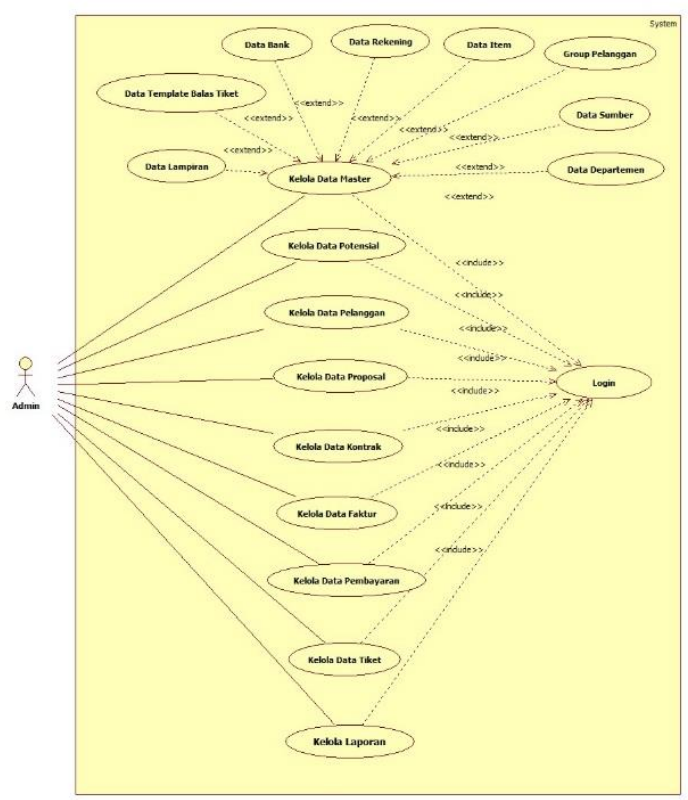

Gambar 3.1Use Case Admin

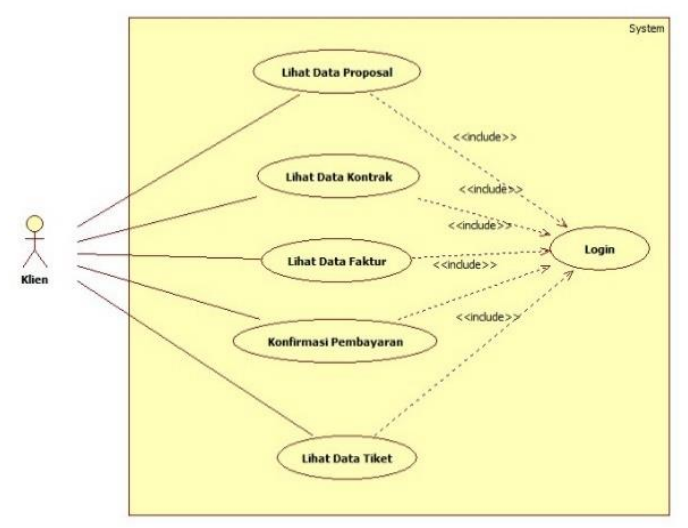

Gambar 3.2 Use Case Klien

\subsubsection{Activity Diagram}

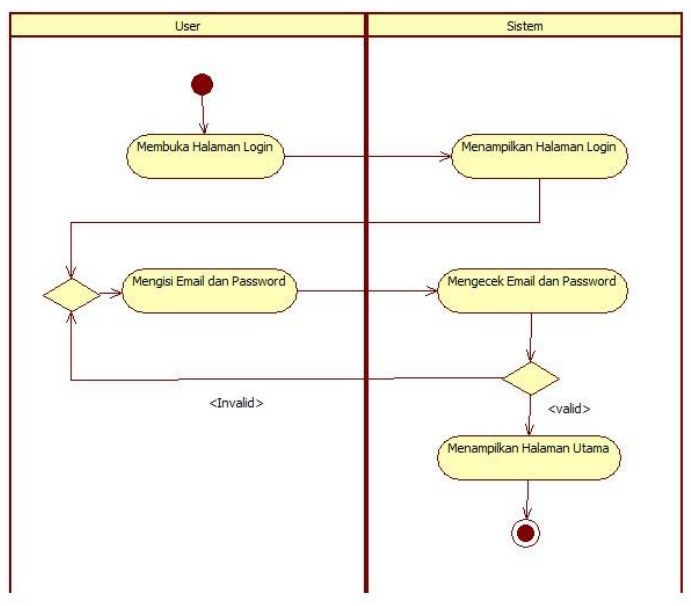

Gambar 3.3 Activity Diagram Login 
JURNAL NUANSA INFORMATIKA

Volume 14 Nomor 1, Januari 2020

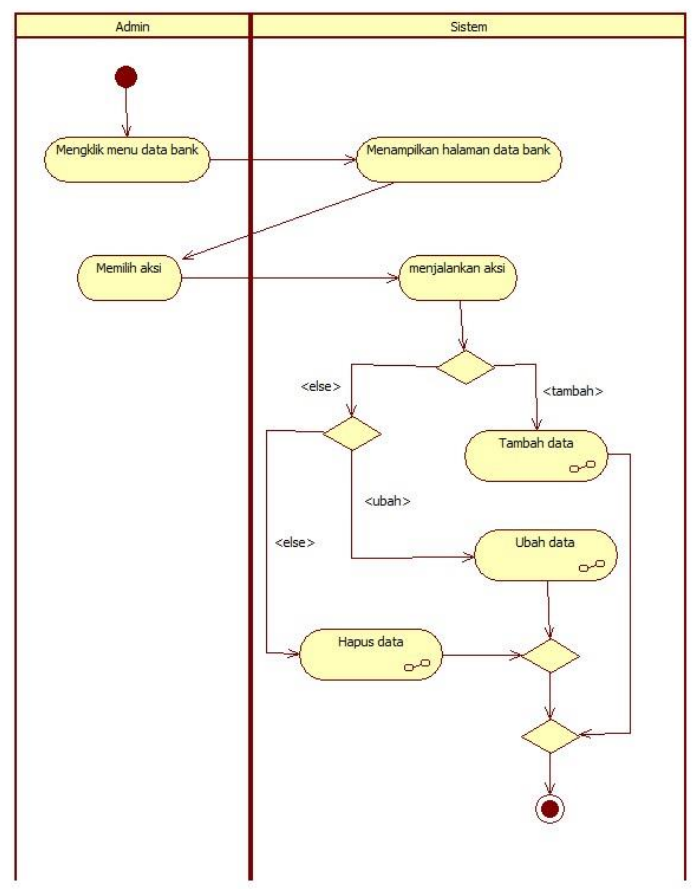

Gambar 3.4 Activity Diagram Kelola Data Master

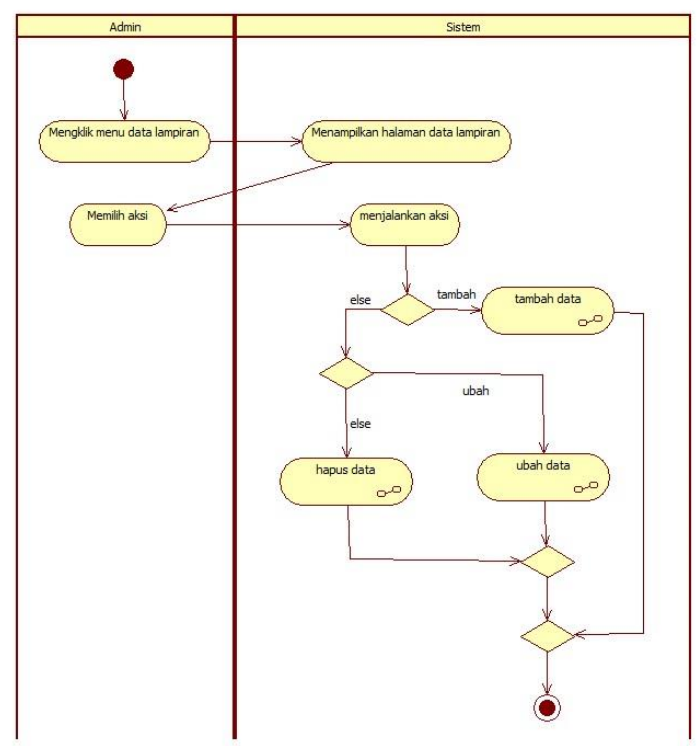

Gambar 3.5 Activity Diagram Kelola Data Master : Data Lampiran
p-ISSN : 1858-3911, e-ISSN : 2614-5405

https://journal.uniku.ac.id/index.php/ilkom

\subsubsection{Sequence Diagram}

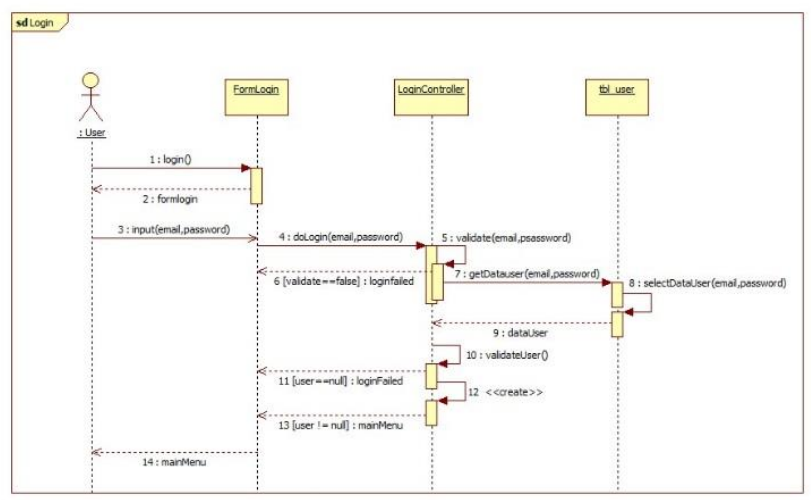

Gambar 3.6 Sequence Diagram Login

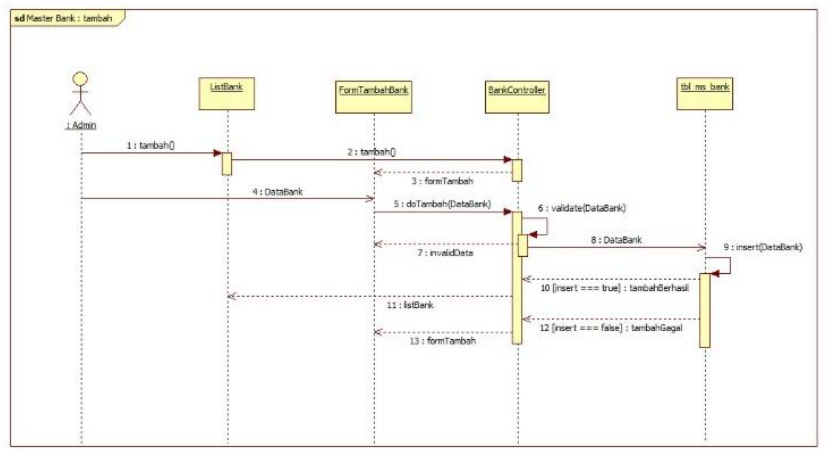

Gambar 3.7 Sequence Diagram Kelola Data Bank

\subsubsection{Class Diagram}

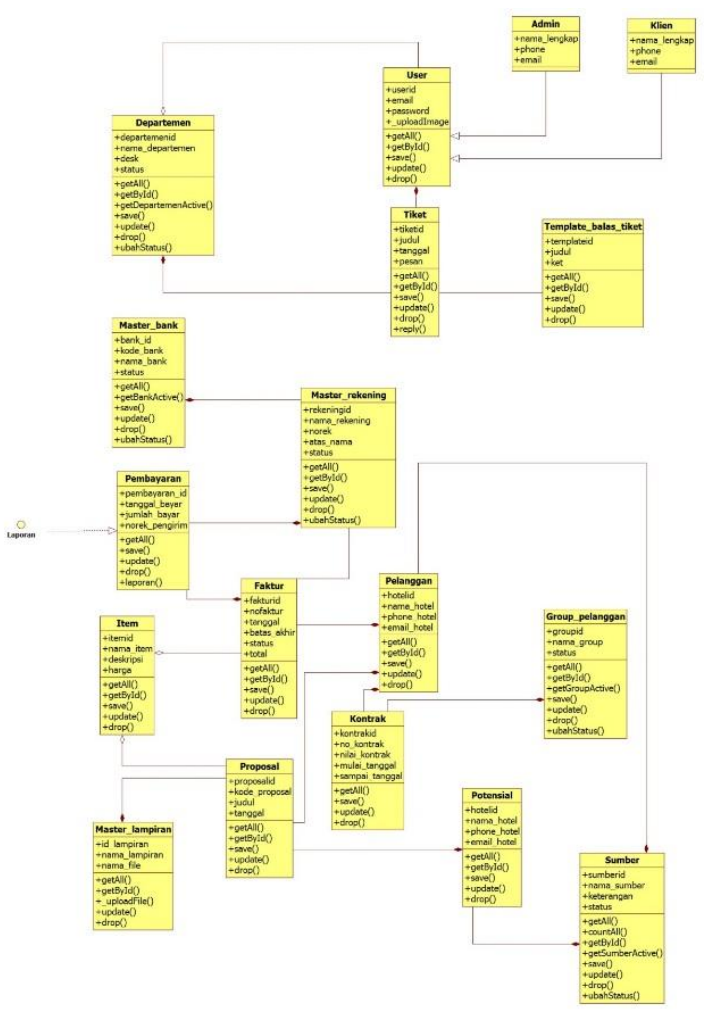

Gambar 3.8 Class Diagram 
JURNAL NUANSA INFORMATIKA

Volume 14 Nomor 1, Januari 2020
p-ISSN : 1858-3911, e-ISSN : 2614-5405

https://journal.uniku.ac.id/index.php/ilkom

\subsection{Hasil}

Berikut ini beberapa tampilan fitur-fitur yang ada pada halaman Admin :

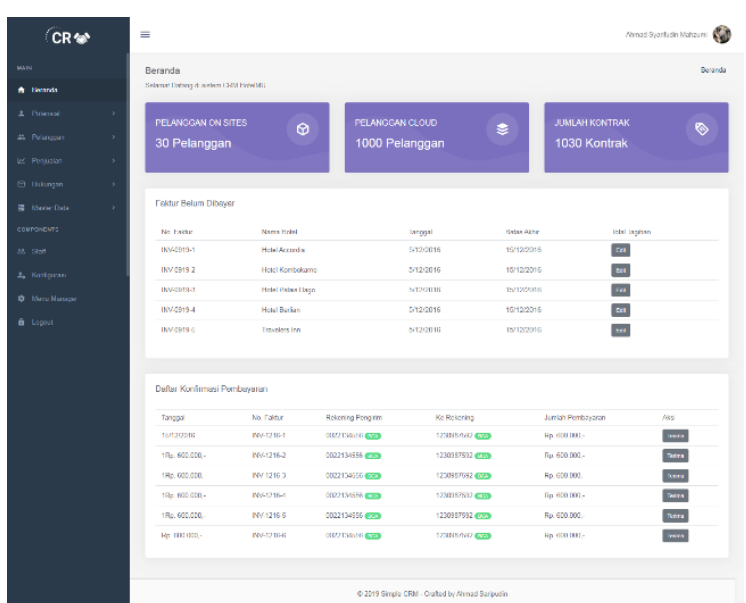

Gambar 3.9 Halaman Admin

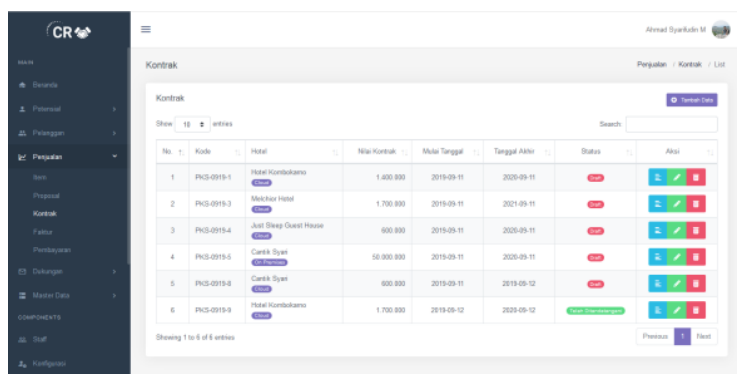

Gambar 3.10 Halaman List Kontrak

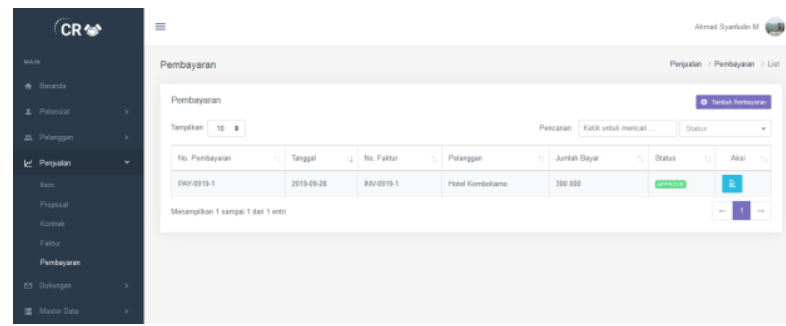

Gambar 3.13 List Pembayaran

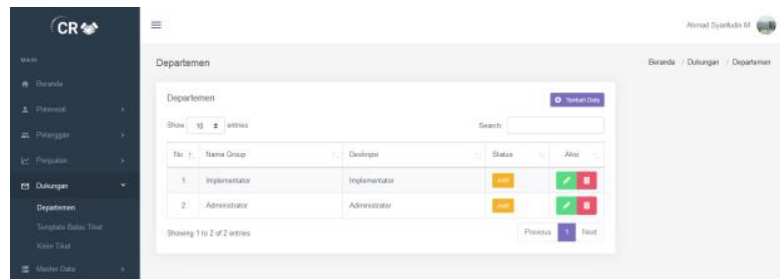

Gambar 3.1 Halaman Departemen

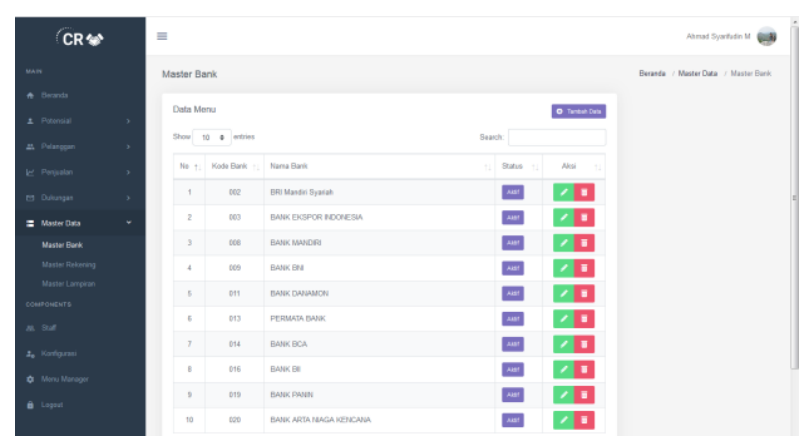

Gambar 3.15 Halaman Master Bank

Berikut ini beberapa tampilan fitur-fitur yang ada pada halaman Client :

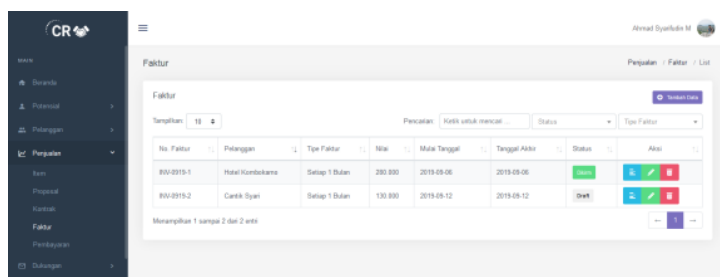

Gambar 3.11 Halaman List Faktur

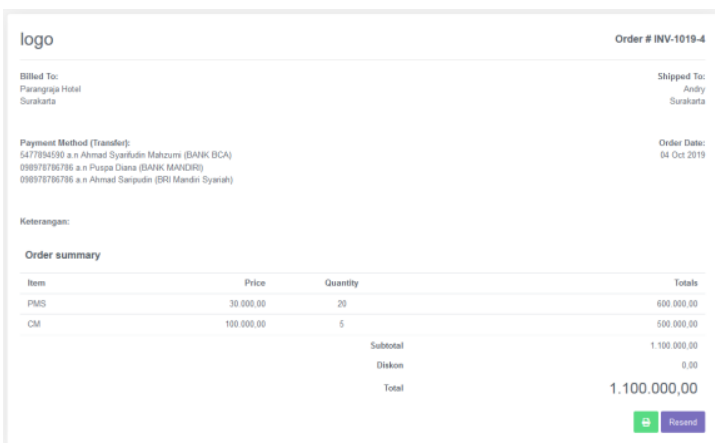

Gambar 3.12 Halaman Detail Faktur

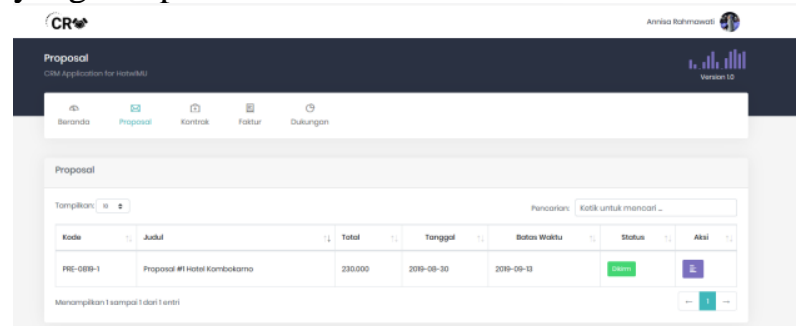

Gambar 3.16 Halaman Proposal Klien

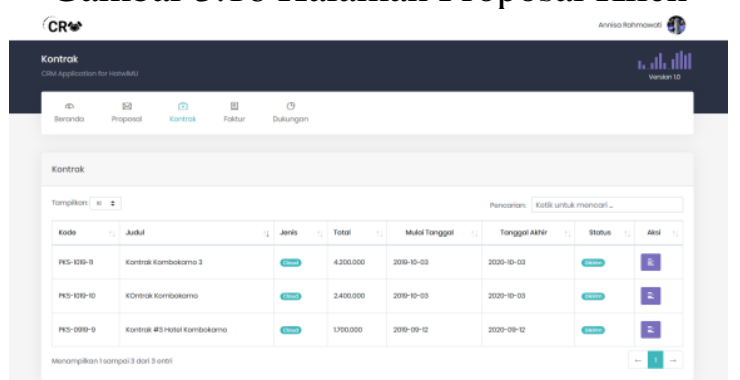

Gambar 3.17 Halaman Tiket Dukungan 
JURNAL NUANSA INFORMATIKA

Volume 14 Nomor 1, Januari 2020
p-ISSN : 1858-3911, e-ISSN : 2614-5405

https://journal.uniku.ac.id/index.php/ilkom

\section{KESIMPULAN}

Berdasarkan hasil pembahasan dan analisis yang telah dilakukan, maka penulis dapat menyimpulkan dengan adanya Pembangunan Sistem Informasi Customer Relationship Management (CRM), pihak perusahaan dapat mengontrol semua klien Hotelmu dengan efektif dan efisien. Sehingga proses rekapitulasi data klien, pembuatan faktur, pembuatan proposal, pembuatan kontrak menggunakan aplikasi khusus, dan data-data tersimpan dalam database dengan aman dan dapat dicari kapan saja dengan efisien. Jadi pihak perusahaan tidak dipusingkan lagi dengan masalah administratif.

\section{SARAN}

Dalam menganalisis Sistem Informasi Customer Relationship Management (CRM) ini masih banyak yang harus dikembangkan, antara lain :

1. Penambahan fitur email broadcast untuk efisiensi pengumuman informasi terhadap klien-klien Hotelmu, seperti informasi development, gangguan pada data center, dan lain-lain.

2. Pembangunan yang sudah dilakukan belum sampai laporan keuangan yang detail. Jadi kedepannya bisa dikembangan sampai laporan keuangan seperti laporan pengeluaran, laporan labarugi, Laporan Arus Kas dan lainlain.

\section{DAFTAR PUSTAKA}

[1] A O'Brien, James, 2005, Pengantar Sistem Informasi Perspektif Bisnis dan Manajerial. Jakarta: Salemba Empat.

[2] Davis B. Gordon. 1985, Kerangka Dasar, Sistem Informasi Manajemen. Seri manajemen No. 90-A: PT Pustaka Binaman Pressindo.

[3] Edhy Sutanta. 2003, Sistem Informasi Manajemen. Yogyakarta : Graha Ilmu.
[4] Fowler, Martin. 2005, UML Distilled Edisi 3. Yogyakarta: Andi.

[5] HM, Jogiyanto. 1999, Analisis dan Desain Sistem Informasi : Pendekatan Terstruktur Teori dan Praktek Aplikasi Bisnis. Yogyakarta: ANDI Yogyakarta.

[6] Kalakota, R. dan Robinson, M.2001, Analisis dan Desain Sistem Informasi : E Business 2.0 Roadmap for Success. Massachusetts: Addsion Wesley Longman.

[7] Kotler, Philip. 2003, Marketing Management. New Jersey: Prentice Hall. Ladjamudin Bin Albahra 2005. Sistem Informasi Manajemen. Yogyakarta : Graha Ilmu.

[8] Marakas. 2006, Management Information System. new york: McGraw-Hill Inc.

[8] Munawar. 2005, Pomodelan Visual dengan UML. Yogyakarta: Graha Ilmu.

[9] Pressman, Roger. 2005, Software Engineering: A Practitioner's Approach. New York: McGraw-Hill.

[10] M. Syafii. 2004, Membangun Aplikasi Berbasis PHP dan My SQL. Yogyakarta: Andi. 